IZA DP No. 7868

Ethnic Spatial Dispersion and Immigrant Identity

Amelie F. Constant

Simone Schüller

Klaus F. Zimmermann

December 2013 


\title{
Ethnic Spatial Dispersion and Immigrant Identity
}

\author{
Amelie F. Constant \\ George Washington University, \\ Temple University and IZA \\ Simone Schüller \\ FBK-IRVAPP \\ and IZA
}

Klaus F. Zimmermann

IZA and Bonn University

\section{Discussion Paper No. 7868 \\ December 2013}

\author{
IZA \\ P.O. Box 7240 \\ 53072 Bonn \\ Germany \\ Phone: +49-228-3894-0 \\ Fax: +49-228-3894-180 \\ E-mail: iza@iza.org
}

Any opinions expressed here are those of the author(s) and not those of IZA. Research published in this series may include views on policy, but the institute itself takes no institutional policy positions. The IZA research network is committed to the IZA Guiding Principles of Research Integrity.

The Institute for the Study of Labor (IZA) in Bonn is a local and virtual international research center and a place of communication between science, politics and business. IZA is an independent nonprofit organization supported by Deutsche Post Foundation. The center is associated with the University of Bonn and offers a stimulating research environment through its international network, workshops and conferences, data service, project support, research visits and doctoral program. IZA engages in (i) original and internationally competitive research in all fields of labor economics, (ii) development of policy concepts, and (iii) dissemination of research results and concepts to the interested public.

IZA Discussion Papers often represent preliminary work and are circulated to encourage discussion. Citation of such a paper should account for its provisional character. A revised version may be available directly from the author. 
IZA Discussion Paper No. 7868

December 2013

\section{ABSTRACT}

\section{Ethnic Spatial Dispersion and Immigrant Identity}

Ethnic groups tend to agglomerate and assemble, mostly in urban areas. While ethnic clustering is critically debated in societies and the consequences for economic outcomes are under debate in research, the process is not yet well understood. A separate literature has also examined the cultural and ethnic identity of immigrants and how these affect their economic performance and societal integration. However, an unexplored channel connects ethnic clustering with ethnic identity formation. Therefore this paper examines the role of ethnic geographic clustering in the sociocultural integration of immigrants. It employs survey data from the German Socio-Economic Panel, combined with disaggregated information at a low geographical level from the unexploited German full census of 1970 and 1987 . We employ the exogenous placement of immigrants during their recruitment in the 1960s and 1970 s and find that local co-ethnic concentration affects immigrants' cultural integration. Residential ethnic clustering strengthens immigrants' retention of an affiliation with their respective country of origin and weakens identification with the host society. The effects are nonlinear and only become significant at relatively high levels of co-ethnic concentration for the minority identity and at very low levels of local concentration for the majority identity. Our findings are robust to the use of an instrumental variable approach.

JEL Classification: J15, R23, Z10

Keywords: ethnic minorities, residential segregation, ethnic identity, spatial dispersion, ethnic enclaves

Corresponding author:

Simone Schüller

FBK-IRVAPP

Via Santa Croce 77

38122 Trento

Italy

E-mail: schueller@fbk.eu 


\section{Introduction}

Western European societies as well as the United States (US) and Canada are confronted with increasing diversity at an ethnic, cultural and religious level. Diversity statistics and projections by the U.S. Census Bureau (2012) show that by 2060, both Hispanic and Asian populations will more than double, the black population will increase from $13.1 \%$ in 2012 to $14.7 \%$ in 2060, American Indian, Alaskan Native, Native Hawaiian and other Pacific Islander populations will double, and the number of people who identify as being two or more races will more than triple over the same period. The geographic location and concentration of ethnics and co-ethnics becomes an important urban/suburban issue, a resource distribution issue, a human, social and ethnic capital issue, a labor market efficiency issue and a future generations' issue. All populations are affected in various ways: the natives, the older arrivals of immigrants and the newcomers.

The rise in diversity has many potential benefits; it may generate economic advantages which can be utilized by both immigrants and the host country, ultimately increasing the creativity and dynamism of society. Select immigration countries, such as Canada, embrace diversity and promote "multi-culti." Others, such as France, perceive it as a threat to or source of conflict with native majority populations. Concerns about the existence of 'parallel societies' in Europe - and the allegedly resulting unwillingness of migrants to fully assimilate into the host country culture occupy public discourse and the media, as well as exacerbate xenophobic attitudes. Recent riots in the UK, France and even Sweden exemplify immigrants' unhappiness and resentment towards their new host country. Potential threats to social cohesion, arising from failed integration, are often linked to the dense ethnic concentration of immigrants which has detrimental consequences for immigrants and the host society as a whole.

Theoretically, ethnic clustering offers both benefits and penalties. Enclaves may provide a sheltered environment, thus reduce the costs of economic and cultural assimilation to the host society, when migrants adjust in groups and not as individuals (Hatton and Leigh, 2011; Aydemir, 2012). Borjas (2000) discussed the beneficial effect of enclaves on the labor market outcomes of immigrants who - due to discrimination - may not be able to compete in the national labor market. The support of co-ethnic business and established clientele are additional positive arguments for the selfemployment of immigrants. On the other hand, enclave living isolates immigrants from the majority society, impedes human capital investments such as in the host country language and other skills, ${ }^{1}$ and decreases the probability of interaction with natives and labor market success.

The empirical economic literature to date has devoted considerable effort to empirically identifying the impact of residential ethnic concentration on immigrant outcomes. For the most part, these studies have examined the impact of enclaves on

\footnotetext{
${ }^{1}$ Contrarily, using data for Canada, Aydemir (2012) provides quasi-experimental evidence that refugees in ethnic enclaves invest more in the native languages, education and training.
} 
the labor market or closely related outcomes (such as language proficiency or education) with varying results. Most recent analyses consistently provide convincing evidence that individuals with unfavorable unobserved characteristics systematically self-select into ethnic enclaves; such negative selection obscures the overall positive or non-negative mean effects of ethnic clustering on immigrants' (and refugees') economic outcomes (Edin et al., 2003 for Sweden; Cutler et al., 2008 for the US; Damm, 2009 for Denmark; Aydemir, 2012 for Canada). Differences in the results often stem from differences in the applied techniques of identification and estimation.

Over the last decade, economists have begun investigating alternative outcomes and exploring cultural and other dimensions of ethnic segregation. Bertrand et al. (2000) provide evidence of enclave effects on welfare participation; Bell and Machin (2012) investigate the link between immigrant concentration and crime; Danzer and Yaman (2013) analyze social interaction. Other important advances in economics came from the seminal work by Akerlof and Kranton (2000), who incorporated the identity of individuals in the utility function and explained previously thought suboptimal economic outcomes. The economic literature concerned with immigrant integration into the host country societies explored these new ideas and studied identity formation (Constant et al., 2009; Constant and Zimmermann, 2013). A number of empirical studies show that the degree to which immigrants relate to the majority culture and to their home country's culture may affect their labor force participation and earnings (Constant and Zimmermann, 2009; Battu and Zenou, 2010), job search behavior and occupational prestige (Pendakur and Pendakur, 2005), and homeownership (Constant et al., 2009). Overall, this literature suggests that immigrants with a relatively strong host country identity perform better in the labor market and that possessing a very strong oppositional identity may have detrimental effects.

Attempts to connect immigrant ethnic concentration to other non-economic outcomes in a host country show that increasing immigration rates in a locality increase the subjective well-being of natives and that this effect is nonlinear and depends on immigrants' ethnic identity (Akay et al., 2012). Fellow social scientists, working on the importance and impact of ethnic/racial identity on a variety of socioeconomic phenomena, find that African-American high-school students with a strong ethnic identity and group pride who were also cognizant of societal discrimination; these students had a positive academic stance and exhibited higher academic achievements than comparable youth who hid their ethnic identities, did not take pride in their group and were not aware of racial discrimination (Chavous et al., 2003). Oyserman and Yoon (2009) used data on Latino and African Americans in the US and find that racial-ethnic segregation undermines positive racial-ethnic identity.

In this paper, we aim to go a step further and study the impact of the local co-ethnic concentration density on the formation of immigrants' feelings of belonging to the host society and culture, on the retention of their affiliation to the culture of origin and any other combination of their ethnic identity. The question we ask is if ethnic agglomeration limits the prospects of cultural integration and belonging. A serious 
hurdle in this type of study is that immigrants' locational choices may be influenced by networks, job opportunities and other confounding factors. Our empirical application is based on survey data from the German Socio-Economic Panel. To address inherent endogeneity issues, we are able for the first time to use unexploited data from the 1987 German census at a disaggregated geographical level.

Second, we circumvent the issue of immigrant self-selection into certain locations by exploiting the quasi-experimental setting of the historical exogenous geographical distribution of immigrants during the German recruitment phase in the 1960s and early 1970s. Since recruitment was purely demand-driven and foreign workers were allocated to specific firms in specific locations before arriving to Germany, the initial geographic placement of immigrants was exogenous to unobserved individual characteristics such as willingness to culturally integrate.

Third, we explore the existence of potential nonlinearities in the enclave effect on ethnic identity. To date, little attention has been paid to the empirical analysis of nonlinearities in economic research concerned with ethnic segregation. Yet, for example Bell and Machin (2012) show that enclave effects (on crime rates) may only become apparent in areas that reach a critical degree of ethnic segregation. There are good reasons to assume that this might also be the case in the context of ethnic identity formation (Bisin et al., 2010).

Our motivation to study the effects of ethnic clustering on immigrant identity formation clearly relates to the wider economic literature on ethnic identity. Given the economic consequences as well as the public debate on immigrant willingness to integrate, it is thus important to understand the mechanisms behind immigrants' identity formation, as a permanent resident population in the host country. Whether or not ethnic segregation matters in this context will contribute to an understanding of whether immigrants cluster in certain locations because they are not willing to integrate or whether their prospects of cultural integration are limited due to residing in an ethnic cluster. The more we understand the process of the ethnic identity and the environmental influences it endures, the better we can understand how to foster integration and achieve full participation.

\section{Background and Previous Literature}

\subsection{Ethnic Clustering and the Formation of Ethnic Identity}

Bisin et al. (2010, 2011) incorporate several theories of identity formation from psychological and sociological research and propose a theoretical framework which allows for two distinct motivational mechanisms of group identity formation: cultural conformity and cultural distinction. ${ }^{2}$ These two mechanisms provide contrasting

\footnotetext{
${ }^{2}$ Cultural conformity is based on "assimilation theories, in political science and sociology and contact theory in social psychology" whereas cultural distinction is based on "theories of multiculturalism, and conflict." (Bisin et al., 2010, pp.2-3).
} 
empirical implications on how residential ethnic segregation might affect immigrants' ethnic identity.

Under the mechanism of cultural conformity, a high degree of ethnic clustering is likely to strengthen in-group loyalties and immigrants are hence more motivated to retain their respective minority identity. On the other hand, with lower concentrations of co-ethnics in the residential area, group boundaries would increasingly blur due to social interaction with natives and progressively lead to the adoption of the host country culture. In contrast, if cultural distinction is the mechanism at play, residing in an area with a low co-ethnic concentration would induce a psychological cost associated with the exposure to cultural differences. Retaining one's own distinctive cultural heritage would then help reduce this cost. Immigrants residing in an area with a relative high density of co-ethnics would have fewer incentives to preserve their minority affiliation, which might in turn favor the process of cultural integration.

Previous empirical evidence on the link between ethnic segregation and immigrant identity formation is extremely sparse and provides mixed results. Based on UK data, Bisin et al. (2010, 2011) show that immigrants' minority identity may be more intense in mixed rather than segregated neighborhoods, which would support the cultural distinction hypothesis. This is consistent with non-economic literature such as Oyserman and Yoon (2009), who use US data and find that racial-ethnic segregation weakens racial-ethnic identity. In contrast, Battu and Zenou (2010) provide evidence for cultural conformity showing that living in an ethnic enclave is associated with very low levels of British identification and a rather strong affiliation with the respective ethnic group.

Danzer and Yaman (2013) were the first to exploit the quasi-experiment of guestworker recruitment in Germany to identify effects of ethnic concentration on social integration. While their results suggest that a high co-ethnic concentration reduces the likelihood of immigrants to socially interact with natives, they find no significant impact of living in an ethnic enclave on individuals' self-reported ethnic identification. This somewhat puzzling result might however be due to the fact that the authors employ a rather wide concept of ethnic enclaves being measured at the regional level of so-called Raumordnungsregionen (on average, these comprise approximately 500,000 inhabitants). Secondly, the impact might be in fact nonlinear and only become significant at relatively high levels of co-ethnic concentration. Moreover, they use information from the 2\%-sample of the German employee population, which does not allow for an accurate calculation of local ethnic composition at the geographical level of counties.

In our study, we examine the link between ethnic clustering and immigrants' ethnic self-identification at the more disaggregated level of counties and investigate nonlinearities in this relationship. We avoid measurement error by using the 1987 German full census, which provides regional information on the full population resident in Germany. 


\subsection{Ethnic Concentration in Germany}

The public debate in many Western European countries often focuses on a perceived lack of immigrants' willingness to fully integrate into the host country society. One persistent claim in this context is that immigrants' tendency to concentrate in certain neighborhoods or counties may inhibit their familiarization with the host country while giving rise to oppositional identities and attitudes. In the German context, the fear of parallel societies and the formation of ethnic neighborhoods are repeatedly topics in the national media. Apart from this recurrent media interest, little is known about the existence and the actual effects of ethnic enclaves in Germany; limited availability of relevant data is also a culprit. In particular, data by immigrant nationality and geographically disaggregated levels are extremely rare. The few studies that exist document a stable, but rather low degree of ethnic segregation in Germany.

Schönwälder and Söhn (2009) examine immigrants' settlement structures in Germany based on data from the 2005 Microcensus as well as city-level data from the Inner-city Spatial Observatory (IRB). They document generally low levels of ethnic residential concentration and segregation within West-German cities with most immigrants residing in mixed neighborhoods. Interestingly, the authors find immigrants' residential structures still reflect the labor demand pattern of the guestworker recruitment era from the 1960s and 1970s. For example, the major settlement locations for the Turkish population still appear to be the Ruhr region, Cologne, Hamburg and Berlin, while Italians and ex-Yugoslavians are more heavily populated in Southern Germany. Furthermore, and in contrast to other European countries, Schönwälder and Söhn (2009) show that the immigrant population in Germany is not predominantly concentrated in the few urban centers but rather distributed over a large number of cities, many of them small- and medium-sized. Glitz (2012) documents the overall levels of ethnic workplace and residential segregation among the active labor force population in Germany using administrative data at the municipality level; the results show that ethnic minority workers are to a lesser extent residentially segregated than they are at their workplace across establishments. These levels of segregation appear to be relatively stable over the period 1975 to 2008 . Interestingly, low-educated workers are significantly more segregated than the higheducated across workplaces, while this is not the case across residential locations.

Our study adds to the literature by comprehensively documenting the extent and pattern of ethnic residential clustering among the main guestworker immigrant groups using information not only on cities or employees but also on the total resident population in Germany. In particular, we exploit data from the 1987 Census, which allow an accurate calculation of the local ethnic composition at a low, geographically disaggregated level with respect to each ethnic group under study. 


\subsection{The Quasi-Experiment of Guestworker Immigration to Germany}

Economic researchers attempting to estimate the causal effects of ethnic segregation on individual outcomes face the empirical challenge of potential endogenous selection of immigrants with unfavorable unobserved characteristics into residential areas with high concentrations of co-ethnics. Previous literature suggests that such a selfselection introduces a considerable negative bias to the estimation and thus the accuracy of the results is critically affected (see, e.g. Edin et al., 2003; Cutler et al., 2008; Damm, 2009). While Cutler et al. (2008) rely on instrumental variable estimation methods, both Edin et al. (2003) and Damm (2009) circumvent the problem of endogenous selection by exploiting dispersal policies of refugees in Sweden and Denmark.

To confront the endogenous selection of immigrants into ethnic clusters, our analysis uses the quasi-experiment of guestworker recruitment to Germany during the 1960 s and 1970s. In the course of the demand-driven recruitment process, guestworker immigrants were allocated across German regions in a way that was exogenous to their intrinsic willingness to integrate in the host society. In fact, the guestworker program was explicitly established to accommodate temporary, not permanent, immigration. The guestworker migrants themselves did not intend to stay permanently in Germany and thus were willing to accept the conditions of the move and job types (Constant, 1998).

Guestworker bi-national treaties were initiated with Italy (in 1955), Greece and Spain (in 1960), Turkey (in 1961) and Yugoslavia (in 1968) to confront the apparent labor shortages in the growing post-war German economy. Recruitment was operationalized by a commission of the Federal Labor Office in cooperation with the respective national labor authority. The commission received requests for workers by German firms and then accordingly allocated applicants to specific employers. Residence permits were issued for the initial duration of one year and were conditional on employment with the assigned firm in a specific locality. Initially, these blue-collar workers were housed in barracks. While eventually they could rent apartments and stay, they did not change locations. After the labor migration ban in 1973, many of the guestworkers, particularly Turks, stayed in Germany and brought their families. Family reunification was also predated upon an existing apartment, residential registration, a job, among other stipulations. All these facts explain the little movement of immigrants within Germany.

\section{Data and Empirical Setup}

\subsection{Data}

We use individual-level data from the nationally representative German SocioEconomic Panel (SOEP) 1987 wave complemented by county-level information from the German full census of 1970 and 1987. All individual level variables are based on the 1987 wave of the SOEP immigrant sample, which provides rich information on 
roughly 2,000 individuals of one of the foreign ethnicities of interest in this analysis. Throughout, we define the individual's ethnicity as the country of origin. Most importantly, these data contain information on immigrants' self-assessed ethnic identity, i.e., their feelings of belonging to the host country society and their origin country culture. Our dependent variables are subjective identity indicators, measured on a five-point scale ranging from "not at all" (1) to "completely" (5).

Local characteristics are measured at the county level. Using data from the German full 1987 census, which covers the entire resident population in Germany, grants the unique opportunity to calculate the exact number of immigrants for this rather disaggregated geographical unit. In 1987 there were 328 counties and the median county had 129,502 inhabitants. ${ }^{3}$ From the full census, we are able to obtain the sizes of the four largest immigrant ethnicities for each county at that time. We use population counts of the number of foreign citizens to represent the size of the respective ethnic group in a county; in contrast to the SOEP, the 1987 census data do not contain information on the country of birth. Note however that in 1987, the naturalization of immigrants was extremely low due to the law of ius sanguis (nationality by descent) and other monetary and bureaucratic hurdles in effect. ${ }^{4}$ It is therefore safe to assume that the number of foreign citizens and the number of foreigners born in a particular country of origin is highly correlated. ${ }^{5}$ Note also that the German full census of 1987 recorded particular citizenship information only for the four largest immigrant nationalities (Turkish, ex-Yugoslavian, Italian and Greek). This means that some quantitatively significant groups such as the Spanish or Portuguese cannot be analyzed separately and are necessarily excluded from the analysis.

\subsection{Basic Information on Residential Ethnic Segregation in Germany}

Before turning to our main analysis, we use the 1987 German census to describe the extent and some basic patterns of the ethnic residential clustering in Germany. Panel A of Table 1 shows that $6.79 \%$ of the resident population in Germany 1987 held a foreign passport. The largest immigrant group is the Turks, who constituted $2.35 \%$ of the total population. Further data in Table 1 illustrate settlement patterns across counties. Foreign citizens represent on average $5.33 \%$ of the population in one county. The highest share of foreigners in one county was $20.40 \%$. The highest population share of one ethnic group (the Turks) in only one county was $7.58 \%$.

Table 1 about here

\footnotetext{
${ }^{3}$ Counties in Germany are an intermediate administrative level between federal states and municipal governments, and correspond to the NUTS-3 level. In 1987, there were 236 rural and 92 urban counties. ${ }^{4}$ A figure based on the naturalization statistics of 1981 - 1997 shows that naturalization was very low before 1989. This figure is available upon request.

${ }^{5}$ Note that the group of foreign citizens also includes German-born individuals who hold a foreign passport.
} 
To which extent do immigrants cluster in "high co-ethnic concentration counties" in 1987 Germany? There is no consensus in the empirical literature about the definition of ethnic segregation. Here, we apply a relative measure and define high local co-ethnic concentration counties as those in which the share of a specific ethnic group is at least twice as high as in Germany as a whole. 6 The national share of coethnics serves as a benchmark since it is the share that one would expect if the respective ethnic group was uniformly distributed across the country. Medium local co-ethnic concentration is then defined as an area in which the share of co-ethnics among the population is higher, but less than twice as high, than the national share of the respective group. A county with a low local concentration of co-ethnics has a coethnic population share lower than the national share. Table 1 demonstrates that the majority of each immigrant group lives in either medium or high concentration counties, that is, in counties with a co-ethnic share that is higher than the national level. There are some differences across ethnic groups when it comes to high concentration areas. While for ex-Yugoslavs, Italians and Greeks the share living in such counties amounts to 40 - 50\%, among Turkish nationals only $21.19 \%$ live in high concentration counties. ${ }^{7}$ Overall, the descriptive evidence suggests that most immigrants tend to cluster and agglomerate in areas with relatively higher shares of resident co-ethnics.

While, as described above, most immigrants appear to live in high co-ethnic concentration counties, there are relatively few of these counties. For each ethnic group Figure 1 displays the distribution of German counties according to the counties' population shares of the respective ethnic group. The histograms show that the majority of German counties have in fact low co-ethnic shares. The first vertical line (closer to the vertical axis) in each graph represents the overall national population share of the respective ethnic group. The second red line indicates twice that share. It is obvious from Figure 1 that there are many fewer counties with medium or high ethnic concentration than low concentration areas. There is hence suggestive evidence of ethnic segregation in Germany. Turks have a much flatter distribution of ethnic concentration across counties than the other ethnicities.

Figure 1 about here

Moreover, we observe marked differences across ethnic groups with respect to their geographic distribution across Germany. The top-five counties in terms of coethnic shares are displayed for each ethnic group at the bottom of Panel A in Table 1. Similar to Schönwälder and Söhn (2009), we find the Turks to be prevalently residing in the Ruhr area, Cologne and Berlin, whereas the other groups rather tend to reside in

\footnotetext{
${ }^{6}$ A similar definition is employed by Borjas (1998) and Edin et al. (2003).

7 Employing a comparable measure of local ethnic concentration in terms of area zip codes, Borjas (1998) finds that $48 \%$ of US residents with a migration background lived in relatively high concentration areas in 1979 with significant dispersion across ethnic groups (e.g., 83.8\% of Mexicans, 49.6\% of Italians, compared to only $25.8 \%$ of Greeks). Such a calculation for Sweden by Edin et al. (2003) shows that in $199742 \%$ of first-generation immigrants resided in ethnic enclaves.
} 
Southern German counties. Figure 2 is a graphical display of ethnic concentration levels in counties across Germany for each ethnic group. As observed in Figure 1, we again note here that immigrant groups tend to cluster in few high concentration counties.

Figure 2 about here

\subsection{Sample and Descriptive Statistics}

We base our analysis on a sample of first-generation migrants, aged 16 and older, who migrated from one of the major guestworker source countries: Turkey, the former Yugoslavia, Italy and Greece. We excluded individuals with missing information on the year of immigration, educational level or ethnic identity. After imposing these restrictions, the final sample based on SOEP data consists of 1,882 individual observations. Local-level information from the German full census is then matched to each of these observations based on the county of residence. There are 117 counties in our sample. ${ }^{8}$

We report summary statistics of the key variables by degree of local co-ethnic concentration in Table 2. As above in Table 1, a low degree of co-ethnic concentration is defined for each ethnic group as counties in which ethnic concentration (that is, the size of the ethnic group relative to the population in the respective county) is lower than the share of this ethnic group in the entire population. A high degree of co-ethnic concentration, on the other hand, entails counties where the local-level share of a respective ethnic group is at least twice as high as the national population share of this group. By comparing the fraction of the co-ethnic population within a county to the fraction that one would expect if the ethnic group was distributed randomly across counties, we basically construct an individual-level measure of segregation similar to the approach employed by Borjas (1998).

\section{Table 2 about here}

The first rows of Table 2 compare the mean levels of self-assessed strength of identification with either the German host country (German identity) and the country of origin (minority identity) for immigrants residing in a low, medium or high coethnic concentration county. With respect to German identity, there seems to be no differences on average between those individuals residing in a county of low co-ethnic concentration and those living in a medium or high concentration county. Immigrants' affiliation with the country of origin appears to be weaker in counties with a medium or high concentration of co-ethnics as opposed to those in which co-ethnics are

\footnotetext{
${ }^{8}$ Among these are 76 rural and 41 urban counties. The average number of observations in a county is 16.09. Since the full universe of the 328 counties is not represented in the SOEP sample, Panel B of Table 1 reproduces the indicators presented in Section 3.2 for the 117 counties represented in the SOEP sample of the 1987 wave. We observe no indications for a potential bias.
} 
relatively rare. This first descriptive evidence seems to be in line with the theoretical and empirical findings of Bisin et al. (2010, 2011) with minority identity being stronger in mixed rather than in segregated areas (cultural distinction).

To econometrically analyze the relationship between co-ethnic concentration and ethnic identity, we include a larger set of control variables consisting of both individual characteristics as well as local area attributes. Table 2 contains the list of these variables. We build on the previous empirical literature concerned with factors of ethnic identity formation (see, e.g. Zimmermann et al., 2008) and include both preand post-migration characteristics of individuals. Pre-migration characteristics are gender, age at entry, and dummies capturing human capital acquired in the country of origin as well as ethnic origin. The post-migration characteristics are years since migration, a dummy variable indicating whether an individual experienced an employment spell in Germany, ${ }^{9}$ and indicator variables capturing human capital acquired in Germany.

Investigating the distribution of pre- and post-migration characteristics across counties with different degrees of co-ethnic concentration gives a first indication of whether immigrants sorted into specific locations along the lines of these observable characteristics. While there seem to be no differences in terms of age at migration or gender, interesting and diverse patterns emerge for the four ethnic groups. While the Turks in our sample are more likely to reside in medium concentration counties rather than in areas with low or even high co-ethnic concentration, no particular preference emerges among individuals from the former Yugoslavia. Italian as well as Greek nationals are more likely to reside in high than medium or low co-ethnic concentration areas. This roughly reflects the pattern observed in Table 1 based on data from the 1987 full census.

There is no indication of distributional differences with respect to pre-migration or post-migration education, with the exception that individuals with incomplete schooling in their respective home country are more likely to reside in areas with a high co-ethnic concentration. When it comes to post-migration characteristics, the only significant differences are in years since migration with individuals who immigrated in earlier years being more likely to reside in high concentration counties. Summarizing the above, there seems to be only weak concern about self-selection in co-ethnic enclaves according to the observed characteristics. This is congruent with the descriptive observations by Schönwälder and Söhn (2009) and the findings of Danzer and Yaman $(2010,2013)$.

The bottom panel of Table 2 presents local characteristics by degree of ethnic concentration. The local native population density, namely the number of German citizens per square kilometer, strongly increases for medium and high relative to low ethnic-concentration counties, which indicates that these are mostly urban areas. Therefore, it is not as surprising that the local unemployment rate is significantly

\footnotetext{
${ }^{9}$ We use SOEP biography data on employment spells to generate an indicator variable that equals one if the individual had worked at any point in the period between the year of immigration and 1987.
} 
lower in counties with a relatively high concentration, which are at the same time the more urbanized locations. The size of the local immigrant population increases with higher co-ethnic concentration, which indicates that ethnic enclaves are likely to be immigrant enclaves as well.

We conclude from the descriptive evidence that sorting on the observed individual characteristics does not seem to be a major problem for the analysis. However, since individuals residing in low and those living in high co-ethnic concentration counties face very different local characteristics, it is important to carefully control for such potentially confounding factors at the local level. Furthermore, since we find considerable differences across ethnic groups, we control for general systematic cultural differences across groups by including ethnic group fixed-effects throughout the empirical analysis.

\section{Empirical Investigations}

\subsection{Empirical Approach: Identifying Effects of Local Ethnic Concentration}

Our approach to estimate the relationship between local co-ethnic concentration and immigrants' subjective strength of affiliation with the host country (German identity) and the country of origin (minority identity) is to use variation within counties across ethnic groups rather than variation across counties. Using within-county variation has the major advantage that we are able to control for observed as well as unobserved common factors at the local level, which affect each ethnic group in the same way. Our estimation equation is thus specified as

$$
I D_{\text {iek }}=\alpha^{*} \ln (\text { ethnic group size })_{e k}+\beta * X_{i e k}+\mu_{k}+\Upsilon_{e}+\varepsilon_{i e k}
$$

where $I D_{\text {iek }}$ represents the self-assessed identity measure (German or minority respectively) of individual $i$ of ethnicity $e$ who lives in county $k$; In(ethnic group size) $e k$ is the log of the number of co-ethnics of individuals of ethnicity $e$ in county $k$; $X_{i e k}$ is a vector of individual characteristics; $X_{k}$ is a vector of local (county-specific) characteristics; and $\gamma_{e}$ is a fixed-effect for each ethnic group. Unobserved determinants of the individual's ethnic identity measure(s) are captured by the error term, $\varepsilon_{\text {iek. }}$. In this specification, as in all proceeding analysis, we cluster the standard errors at local (county) and ethnic-group level.

By including fixed-effects for each county $\left(\mu_{k}\right)$ and for each ethnic group $\left(\gamma_{e}\right)$ at the same time, we exploit only variation in local ethnic concentrations that is not systematic across ethnicities or across counties. Hence, we control for the average systematic differences across counties and across ethnic groups in any observable or unobservable variable.

Following the approach by Edin et al. (2003) and Damm (2009), equation (1) employs the log of the local co-ethnic group size as the key explanatory variable and 
imposes log-linearity. However, some recent empirical evidence on enclave effects (Bell and Machin, 2012) studying crime outcomes suggests the existence of potential nonlinearities. More importantly, Bisin et al. (2010) find significant nonlinearities in the relationship between ethnic concentration and minority identity in the UK. To explore nonlinearities in this context, we employ the enclave measures defined above in Sections 3.1 and 3.2 (see also Tables 1 and 2) indicating medium and high co-ethnic concentration relative to the national population share of each ethnic group. We consider the following equation

$$
I D_{i e k}=\alpha_{1} * \mathrm{MedC}_{e k}+\alpha_{2} * \mathrm{HighC}_{e k}+\beta * X_{i e k}+\mu_{k}+\Upsilon_{e}+\varepsilon_{i e k}
$$

where $M e d C_{e k}$ is an indicator variable equal to one if the population share of ethnic group $e$ in county $k$ is higher, but less than twice as high, than the national population share of this group; $H i g h C_{e k}$ is a dummy variable indicating whether the ethnic concentration of group $e$ in county $k$ is at least twice as high as its national share.

In equation (1) and (2), local (co-)ethnic concentration is assumed to be exogenously determined since the guestworker recruitment scheme allocated immigrants to firms across Germany. Indeed, from Table 2 we saw no evidence of sorting according to observable characteristics, which is consistent with our assumption of exogenous placement. Danzer and Yaman $(2010,2013)$ find no evidence for negative sorting in the German context of guestworker immigrants either; additionally they show that changes in immigrants' locations in the years after recruitment were not selective along observable characteristics. However, a selection bias might still be influencing our estimates if, during the years after initial placement, individuals had systematically sorted into or out of enclaves according to unobserved characteristics which are related to ethnic identity formation. Additional immigration flows in the course of family reunification after the end of the guestworker recruitment phase could potentially bias our results if inflows into highly segregated areas were systematically different in terms of unobservable characteristics from inflows into counties with lower concentrations of co-ethnic residents.

Therefore, to more carefully address the issue of potential endogenous sorting across counties, we employ an instrumental variable strategy as a robustness check. For such a strategy to be successful, we require a variable that significantly influences local co-ethnic concentration in 1987, but it is not directly associated with the dependent variable for other, independent reasons. We instrument for local enclave measures by the same indicator variable constructed using data from the 1970 full census, that is, we use county-level ethnic concentration shortly before the guestworker recruitment was banned in 1973 to predict local ethnic segregation levels in 1987. Note that the initial geographic distribution of guestworker immigrants has been exogenous during the recruitment phase and these settlement patterns have been strongly persistent since then. In introducing this instrumental strategy, we attempt to account for any remaining potential bias of our OLS estimates due to the tendency of immigrants with more (less) unobservable intrinsic motivation for 
cultural integration to self-select into (out of) ethnic enclaves.

In implementing this instrument, we face the practical difficulty of several reforms of county territories between the 1970 and the 1987 census in some federal states. We are able to retrace these changes in cases where entire counties or their main parts were merged and have to necessarily ignore relatively minor changes. In practice, we match each 1970-county to a county in 1987 and compute enclave indicators based on the 1970 information. We then use the resulting local enclave measure to instrument the respective enclave measure for each county in 1987.

\subsection{Main Results}

Table 3 reports the main estimation results according to equations (1) and (2). The analysis relates the county-level co-ethnic concentration experienced by immigrants of the four main guestworker ethnicities in Germany to the strength of their subjective identification with either the host country (Germany) or the respective culture of origin. Columns (1) and (3) show results employing a log-linear measure of ethnic concentration. Columns (2) and (4) include indicators of medium and high residential segregation to test potential nonlinearities. Both types of specifications control for sets of demographic, pre- and post-migration characteristics, and include both county and country-of-origin fixed effects. Throughout the analysis, the reported standard errors are cluster-robust at the ethnic group and county level.

Overall results indicate that immigrants residing in a county where their specific ethnic group is relatively strongly concentrated feel less German and more affiliated to their culture of origin than immigrants residing in the same county, but whose ethnic group is relatively less present in this location. We clearly observe that the enclave effect is nonlinear with respect to both German and minority identity. The effects only become significant at relatively high levels of co-ethnic segregation (w.r.t. minority identity) and at very low levels of local concentration (w.r.t. majority identity) respectively. That is, the nonlinear pattern is different for host and home country identity.

When allowing for nonlinearities in Column (2) of Table 3, we find that immigrants facing medium or high co-ethnic concentrations in their county of residence on average state significantly lower levels of German identity than those among low coethnic concentrations. Interestingly, there appears to be no significant further difference in German identity between the medium and the high category. Within a county, the difference in German identification between a migrant belonging to a lowlevel segregated group and a migrant experiencing medium or high levels of local coethnic segregation amounts to about $45 \%$ of one standard deviation. In turn, ceteris paribus, an immigrant appears to have the greatest chance of adopting a relatively strong German identity when residing in a low co-ethnic concentration county.

Column (4) of Table 3 shows the nonlinear pattern with respect to minority identity. In this case, we find no significant differences between low and medium coethnic concentration, whereas an enclave effect becomes apparent and significant for 
very high levels of local ethnic segregation. In terms of magnitude, residing in such an enclave increases an immigrant's strength of minority identity by 0.335 standard deviations.

Table 3 further suggests that a relatively stronger German identity is generally more prevalent among immigrants with more time in the host country, those who immigrated at younger ages and those with more education. Education acquired in both home as well as host country play a positive role with predictably stronger effects of education acquired in Germany. Whether or not an immigrant held an employment spell at any time since migration does play a positive but insignificant role. These patterns are mainly mirrored in the opposite direction with respect to minority identity. A notable exception is host country schooling, which does not seem to play a significant role for immigrants' tendency to retain a strong affiliation with the culture of origin.

In comparison with immigrants from Turkey, immigrants from the former Yugoslavia seem to exert, on average, a stronger affiliation to the host country and weaker retention of ties to their country of origin. The Greek, on the other hand, are less inclined to identify with Germany and tend to retain stronger ties to the Greek culture than Turkish immigrants. There are no marked differences in ethnic identity between the Turkish and the Italian immigrant community.

\subsection{Robustness Checks}

Thus far, we have treated the local co-ethnic concentration an immigrant faces in his county of residence as being exogenously given. We have based this assumption on evidence from previous research and our own descriptive findings of no evident systematical sorting on observable characteristics. To further test whether there is additional threat to a causal interpretation of the coefficient estimates presented in Table 3, we employ an IV strategy.

Table 4 and 5 provide the instrumental variable estimates for German and minority identity respectively. Here, we essentially exploit the exogenous initial guestworker placement across German counties during the recruitment years (based on previous respective co-ethnic concentrations measured in the 1970 full census). Throughout the robustness analysis, we employ a binary measure of local co-ethnic concentration. Since in our main analysis we found that effects are nonlinear and become significant only at very low levels of local concentration for the majority identity and relatively high levels of co-ethnic segregation for the minority identity, we group concentration levels accordingly. In particular, with respect to German identity, we employ an indicator variable taking the value of zero if local co-ethnic concentration is low and equal to one in the case of medium or high co-ethnic concentration in a county. Similarly, for the minority identity we construct an indicator of very high levels of local co-ethnic concentration, which is zero in the case of low or medium levels. Control variables are the same as in our main analysis, and as above, we include country of origin as well as county fixed effects in all models. 
The first column in both Table 4 and 5 reports OLS results for the alternative specification employing the binary measures of ethnic concentration as described above. Note that the main results appear to be robust to the change in specification. IV estimates are presented in the final three columns of Tables 4 and 5. Column 2 reports the results of a 2SLS instrumental approach using a linear model in the first stage, while Column 3 shows results of an IV procedure using a probit regression in the first stage. The latter approach takes the binary nature of our endogenous regressor into account. Finally, Column 4 reports the reduced form estimates using the instrument directly in the OLS formulation.

Overall, the IV estimates show a broadly similar pattern as the OLS results. Both IV estimates are of a similar magnitude in comparison with OLS. With respect to German identity, the IV employing a probit first stage is statistically significant and even slightly larger than OLS, whereas the model with a linear first stage is smaller in size, but imprecisely estimated. With respect to minority identity, the IV estimate using a linear first stage is very similar to the OLS estimate, positive and significant, while the IV estimate based on a probit first stage is only slightly smaller and not statistically significant. The IV results hence largely suggest that the potential bias of our main estimates due to immigrants' systematic sorting tendencies is not large.

\subsection{Discussion}

Living in an area where other co-ethnic immigrants tend to cluster appears to reduce the likelihood of an immigrant's self-identification with the host country society and increases identification with the country of origin in a statistically significant nonlinear way. Contrarily, residing in a low co-ethnic concentration county predicts a relatively strong German identity. The enclave effect on the minority identity is negative for very high levels of local ethnic segregation. Such an identification pattern has been shown to affect labor force participation (Constant and Zimmermann, 2009) and homeownership (Constant et al., 2009) negatively, but not wages (Constant and Zimmermann, 2009). Our results are based on an intensive empirical investigation in which core specifications control for sets of demographic, pre- and post-migration characteristics. They include both county and country-of-origin fixed effects and the reported standard errors are cluster-robust at both the country-of-origin and county level. A number of robustness checks with IV estimation, using for the first time full 1970 census data on co-ethnic spatial dispersion, confirm stable signs and sizes of the coefficients, although with some variations in precision.

Under cultural conformity (Bisin et al., 2010, 2011), a high degree of ethnic clustering is likely to strengthen in-group loyalties and immigrants are hence more motivated to retain their respective minority identity and to ignore investments in the majority identity. On the other hand, the more sheltered environment may reduce the costs of economic and cultural assimilation to the host society, when migrants adjust in groups and not as individuals (Hatton and Leigh, 2011; Aydemir, 2012), and hence ethnic clusters may affect majority identity formation positively. However, group 
assimilation may not automatically generate rising majority identity in combination with a decline in minority identity if one allows for multi-ethnic identities (Constant et al., 2009); minority identity may remain strong. Under cultural distinction, residing in a low co-ethnic concentration area induces a psychological cost due to the exposure to cultural differences, whereas minority identity helps to reduce this cost. Immigrants living in areas with relative high clusters of co-ethnics do not need to preserve their level of minority identity, which might then ease the process of majority identity adaption.

Our empirical results suggest that non-linear ethnic clustering affects the majority identity of migrants negatively and their minority identity positively. This rejects both cultural distinction and group assimilation, but confirms cultural conformity.

\section{Summary and Conclusions}

Most nations are characterized by some form of ethnic diversity. Such cultural dispersions will likely increase in the future, fostered also by a growing importance of migration. However, ethnic diversity is not evenly distributed within the countries; immigrants tend to agglomerate mostly in urban areas. While ethnic clustering is critically debated in societies due to unclear economic and social outcomes, previous research has not studied the effects of ethnic concentration on ethnic identity formation sufficiently well. We close this gap by providing a rigorous analysis using unique survey data on identity formation in combination with full census data from 1970 and 1987 for Germany.

The empirical application is based on survey data from the German SocioEconomic Panel. To address inherent endogeneity issues, we are able for the first time to use so far unexploited data from the 1987 German census at a disaggregated geographical level. In addition, we circumvent the issue of immigrant self-selection into certain locations by exploiting the quasi-experimental setting of the historical exogenous geographical distribution of immigrants during the 1960s and early 1970s guestworker recruitment phase in Germany. Since recruitment was purely demanddriven and foreign workers were allocated to specific firms in specific locations before arriving to Germany, the initial geographic placement of immigrants was exogenous to unobserved individual characteristics, such as willingness to culturally integrate. Immigration statistics in Germany show that this locational distribution has been preserved through the years, despite the ban on labor recruitment coupled with increased family reunification. Our study thus explores quasi-experimental evidence.

Our analysis shows that living in an area where fellow co-ethnic immigrants tend to cluster appears to reduce the likelihood of an immigrant's self-identification with the host country society. Residential ethnic clustering strengthens immigrants' affiliation with the respective country of origin. Interestingly, the effects are nonlinear and become significant only at relatively high levels of co-ethnic concentration for the minority identity and at very low levels of local concentration for the majority identity. Our findings are robust to the use of an instrumental variable approach. 
These findings can be understood in the context of the cultural conformity literature, where a high degree of ethnic clustering is predicted to improve in-group loyalties. Therefore, immigrants feel more obliged to keep their minority identity and reduce activities to invest in the majority identity. A policy conclusion could be that ethnic clusters in urban centers should either be avoided or better used to provide incentives for joint ethnic integration activities if a larger majority identity of migrants is desirable.

\section{Acknowledgements}

The survey data used in this paper were made available by the Socio-Economic Panel Study (SOEP) at the German Institute for Economic Research (DIW Berlin). The German 1970 and 1987 censuses were made available by the Federal Statistical Office of Germany (Destatis). We are grateful for excellent support by the statistical offices in Düsseldorf and Bad Ems. Financial support from the German Science Foundation (DFG) for the project on "Ethnic Diversity and Labor Market Success" in the DFG-Priority Program "Flexibility in Heterogeneous Labor Markets" is gratefully acknowledged. The authors thank Martin Fischer, Corrado Giulietti and participants of the IZA Brownbag Seminar for helpful comments and Victoria Finn for editorial assistance. All remaining errors are our own. 


\section{References}

Akerlof, G.A., Kranton, R.E., 2000. Economics and Identity. Quarterly Journal of Economics 115(3), 715-753.

Akay, A., Constant, A.F., Giulietti, C., 2012. The Impact of Immigration on the Well-Being of Natives. IZA Discussion Paper 6630, Institute for the Study of Labor (IZA), Bonn.

Aydemir, A., 2012. Ethnic Enclaves and Human Capital Investments: Evidence from a Natural Experiment, mimeo.

Battu, H., Zenou, Y., 2010. Oppositional Identities and Employment for Ethnic Minorities: Evidence from England. The Economic Journal 120(542), 52-71.

Bell, B., Machin, S., 2012. Immigrant Enclaves and Crime. Journal of Regional Science 53(1), 118141.

Bertrand, M., Luttmer, E.F.P., Mullainathan, S., 2000. Network Effects and Welfare Cultures. Quarterly Journal of Economics 115(3), 1019-1055.

Bisin, A., Patacchini, E., Verdier, T., Zenou, Y., 2010. Bend it like Beckham: Ethnic Identity and Integration. IZA Discussion Paper 5234, Institute for the Study of Labor (IZA), Bonn.

Bisin, A., Patacchini, E., Verdier, T., Zenou, Y., 2011. Formation and Persistence of Oppositional Identities. European Economic Review 55 (8), 1046-1071.

Borjas, G.J., 1998. To Ghetto or Not to Ghetto: Ethnicity and Residential Segregation. Journal of Urban Economics 44(2), 228-253.

Borjas, G. J., 2000. Ethnic Enclaves and Assimilation. Swedish Economic Policy Review 7, 89-122.

Chavous, T.M., Bernat, D., Schmeelk-Cone, K., Caldwell, C., Kohn-Wood, L.P., Zimmerman, M.A., 2003. Racial Identity and Academic Attainment among African American Adolescents. Child Development 74(4), 1076-1091.

Constant, A.F., 1998. The Earnings of Male and Female Guestworkers and their Assimilations into the German Labor Market: A Panel Study 1984 - 1993. Ph.D. Dissertation, Vanderbuilt University.

Constant, A.F., Gataullina, L., Zimmermann, K.F., 2009. Ethnosizing Immigrants. Journal of Economic Behavior and Organization 69(3), 274-287.

Constant, A.F., Roberts, R., Zimmermann, K.F., 2009. Ethnic Identity and Immigrant Homeownership. Urban Studies 46(9), 1879-1898.

Constant, A.F., Zimmermann, K.F., 2009. Work and Money: Payoffs by Ethnic Identity and Gender, in: Constant, A.F., Tatsiramos, K., Zimmermann, K.F. (Eds.), Ethnicity and Labor Market Outcomes, vol. 29, in: Research in Labor Economics, Emerald Group Publishing Limited, Bingley, pp.3-30.

Constant, A.F., Zimmermann, K.F., 2013. Migration and Ethnicity: An Introduction, in: Constant, A.F., Zimmermann, K.F. (Eds.), International Handbook of the Economics of Migration, Edward Elgar Publishing, Cheltenham, pp.13 - 35.

Cutler, D.M., Glaeser, E.L., 1997. Are Ghettos Good or Bad? Quarterly Journal of Economics 112(3), 827-872.

Cutler, D.M., Glaeser, E.L., Vigdor, J.L., 2008. When are Ghettos Bad? Lessons from Immigrant Segregation in the United States. Journal of Urban Economics 63 (3), 759-774.

Damm, A.P., 2009. Ethnic Enclaves and Immigrant Labor Market Outcomes: Quasi- Experimental Evidence. Journal of Labor Economics 27(2), 281-314. 
Danzer, A.M., Yaman, F., 2010. Ethnic Concentration and Language Fluency of Immigrants in Germany. IZA Discussion Paper 4742, Institute for the Study of Labor (IZA), Bonn.

Danzer, A.M., Yaman, F., 2013. Do Ethnic Enclaves Impede Immigrants' Integration? Evidence from a Quasi-Experimental Social-Interaction Approach. Review of International Economics 21(2), 311-325.

Edin, P.-A., Fredriksson, P., Aslund, O., 2003. Ethnic Enclaves and the Economic Success of Immigrants - Evidence from A Natural Experiment. Quarterly Journal of Economics 118(1), 329-357.

Glitz, A., 2012. Ethnic Segregation in Germany. IZA Discussion Paper 6841, Institute for the Study of Labor (IZA), Bonn.

Hatton, T.J., Leigh, A., 2011. Immigrants Assimilate as Communities, Not just as Individuals. Journal of Population Economics 24(2), 389-419.

Oyserman, D., Yoon, K.-I., 2009. Neighborhood Effects on Racial-Ethnic Identity: The Undermining Role of Segregation. Race and Social Problems 1, 67-76.

Pendakur, K., Pendakur, R., 2005. Ethnic Identity and the Labour Market, mimeo, Simon Fraser University.

Schönwälder, K., Söhn, J., 2009. Immigrant Settlement Structures in Germany: General Patterns and Urban Levels of Concentration of Major Groups. Urban Studies 46(7), 1439-1460.

U.S. Census Bureau. 2012. U.S. Census Bureau Projections Show a Slower Growing, Older, More Diverse Nation a Half Century from Now. Release CB12-243. Retrieved from: https://www.census.gov/newsroom/releases/archives/population/cb12-243.html.

Zimmermann, L., Gataullina, L., Constant, A.F., Zimmermann, K.F., 2008. Human Capital and Ethnic Self-Identification of Immigrants. Economics Letters 98(3), 235-239. 
Figure 1: Distribution of Ethnic Concentration across Counties by Ethnic Group

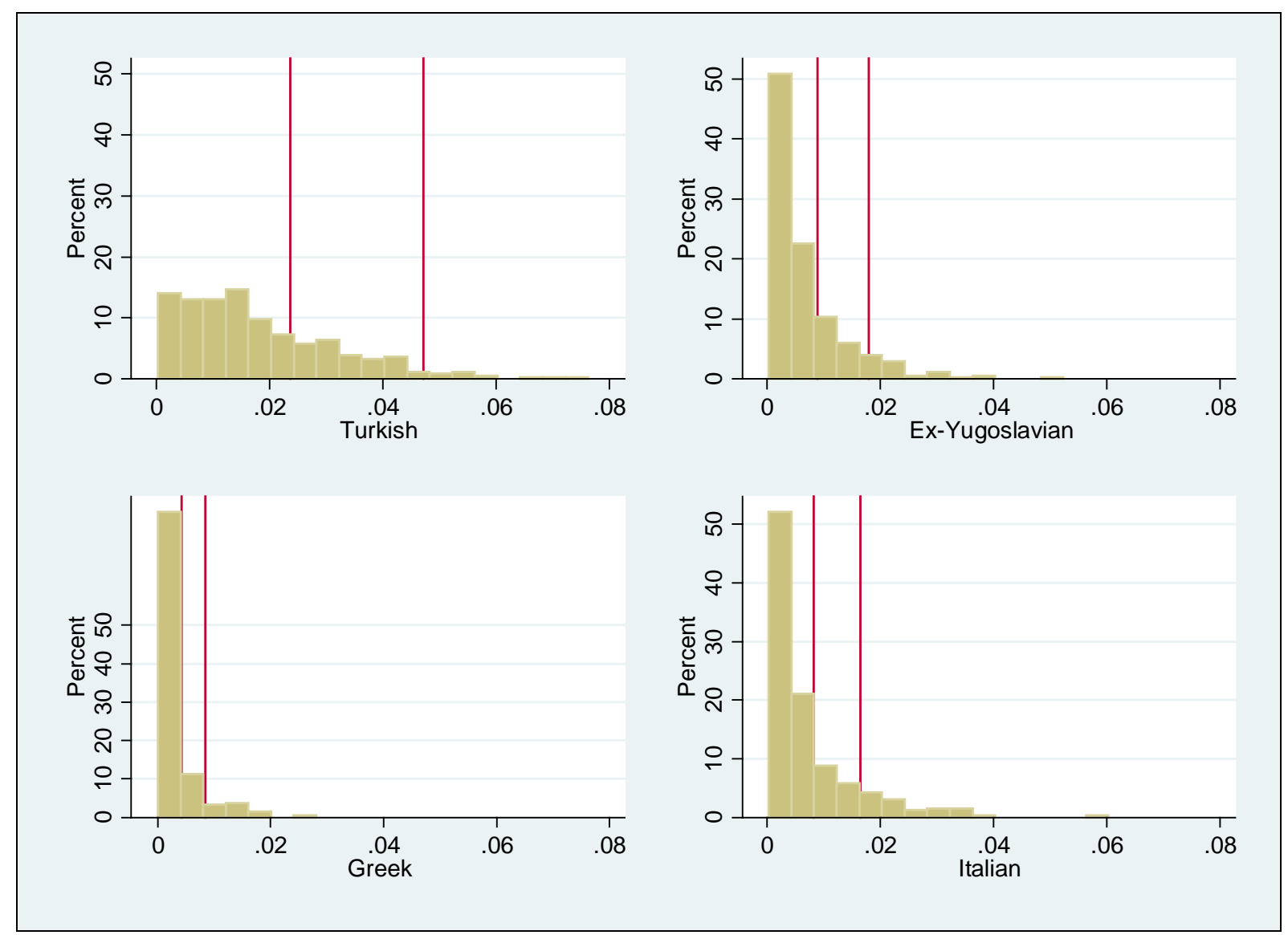

Source: German census 1987, own calculations. County-level information.

Notes: The first vertical line indicates the national population share of the respective ethnic group. The second vertical line represents twice that share. 
Figure 2: Geographical Concentration of Selected Ethnic Groups across Germany

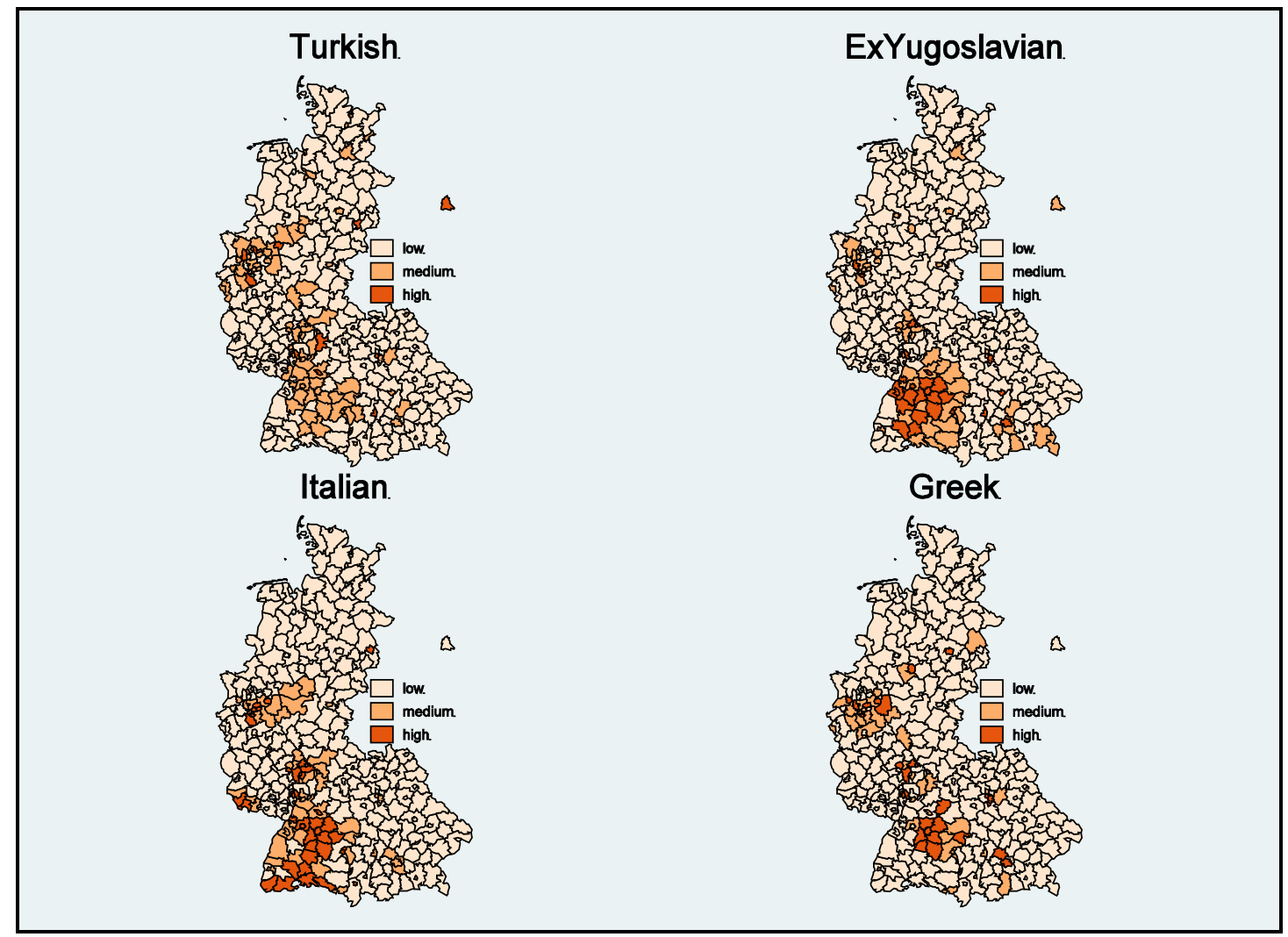

Source: German census 1987, own calculations. County-level information.

Notes: A low (medium, high) co-ethnic concentration is defined as a county with a local co-ethnic fraction which is lower (at least as high, at least twice as high) as the national population share of the respective group. Darker areas denote higher co-ethnic concentration counties. 
Table 1: Ethnic Concentration in Germany - German Census 1987

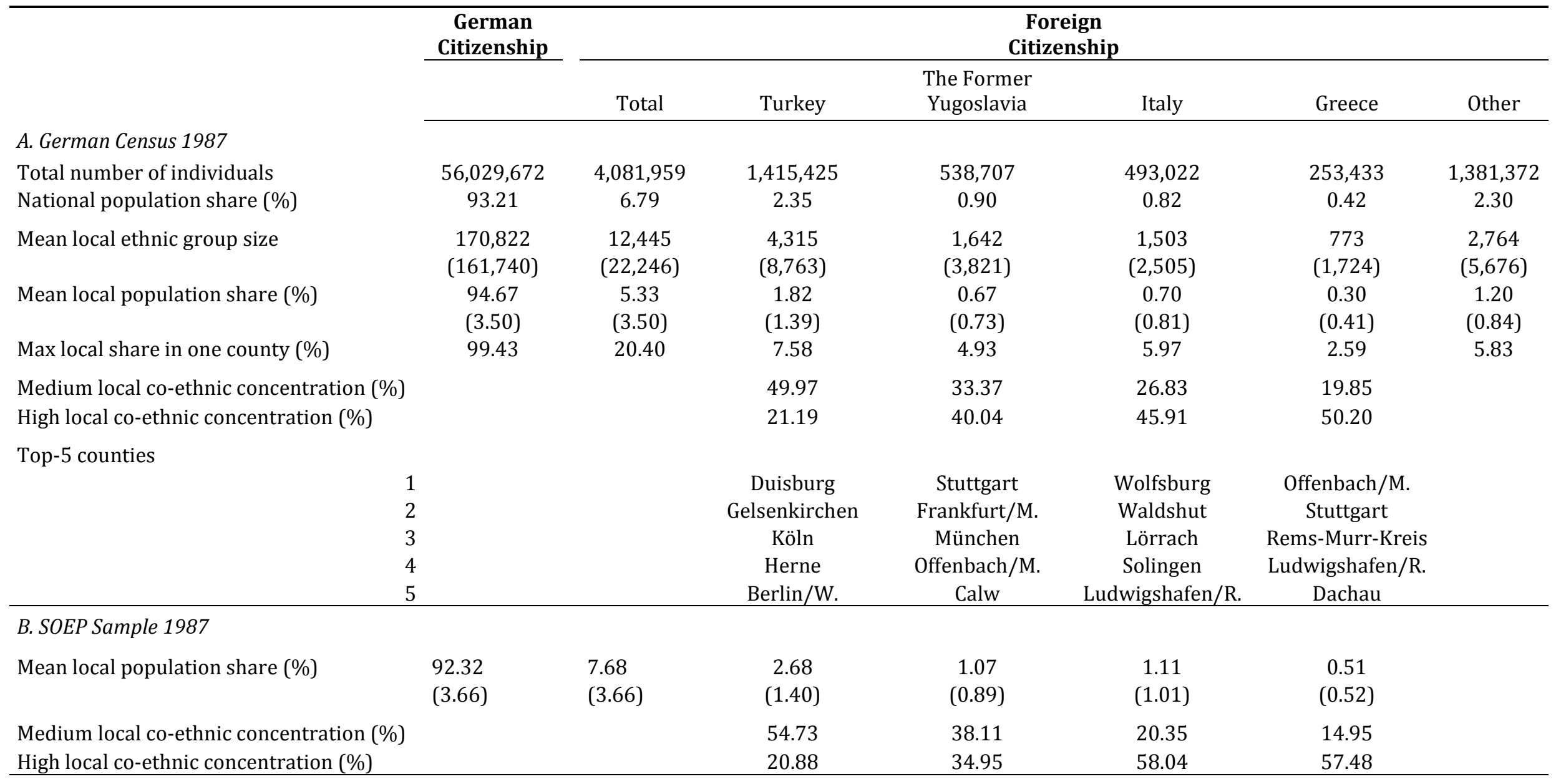

Source: German census 1987, own calculations.

Note: Local level is county level (total 328 counties). Standard deviations in parentheses. Ethnic concentration is the size of the ethnic group relative to the population in each county. A low (medium, high) co-ethnic concentration is defined as a county with a local co-ethnic fraction which is lower (at least as high, at least twice as high) as the national population share of the respective group. 
Table 2: Descriptive Statistics of Main Variables by Co-Ethnic Concentration

\begin{tabular}{|c|c|c|c|c|c|c|}
\hline & \multicolumn{6}{|c|}{ Co-Ethnic Concentration } \\
\hline & \multicolumn{2}{|c|}{ Low } & \multicolumn{2}{|c|}{ Medium } & \multicolumn{2}{|c|}{ High } \\
\hline & Mean & Std. Dev & Mean & Std. Dev & Mean & Std. Dev \\
\hline German Identity (1-5) & 1.936 & $(1.045)$ & 1.921 & $(1.050)$ & 2.048 & $(1.075)$ \\
\hline Minority Identity (1-5) & 4.406 & $(0.881)$ & $4.247^{*}$ & $(1.004)$ & $4.230^{*}$ & $(0.983)$ \\
\hline Female & 0.459 & $(0.499)$ & 0.454 & $(0.498)$ & 0.451 & $(0.498)$ \\
\hline Age at Migration & 22.983 & $(10.567)$ & 22.295 & $(10.315)$ & 22.291 & $(10.614)$ \\
\hline Turkey & 0.402 & $(0.491)$ & $0.599^{*}$ & $(0.491)$ & $0.227^{*}$ & $(0.419)$ \\
\hline The Former Yugoslavia & 0.237 & $(0.426)$ & 0.223 & $(0.416)$ & 0.203 & $(0.403)$ \\
\hline Italy & 0.184 & $(0.388)$ & $0.115^{*}$ & $(0.319)$ & $0.326^{*}$ & $(0.469)$ \\
\hline Greece & 0.177 & $(0.382)$ & $0.064^{*}$ & $(0.245)$ & 0.244 & $(0.430)$ \\
\hline \multicolumn{7}{|l|}{ Pre-migration education } \\
\hline no schooling in home country & 0.205 & $(0.404)$ & 0.177 & $(0.382)$ & 0.175 & $(0.380)$ \\
\hline college in home country & 0.013 & $(0.113)$ & 0.014 & $(0.118)$ & 0.018 & $(0.134)$ \\
\hline vocational training in home country & 0.265 & $(0.442)$ & 0.247 & $(0.431)$ & 0.220 & $(0.415)$ \\
\hline complete schooling in home country & 0.306 & $(0.461)$ & 0.309 & $(0.463)$ & 0.278 & $(0.448)$ \\
\hline incomplete schooling in h. country & 0.212 & $(0.409)$ & 0.252 & $(0.435)$ & $0.309^{*}$ & $(0.462)$ \\
\hline \multicolumn{7}{|l|}{ Post-migration education } \\
\hline some schooling in Germany & 0.652 & $(0.477)$ & 0.662 & $(0.473)$ & 0.612 & $(0.488)$ \\
\hline no degree in Germany & 0.340 & $(0.474)$ & 0.336 & $(0.473)$ & 0.378 & $(0.485)$ \\
\hline higher degree in Germany & 0.009 & $(0.092)$ & 0.001 & $(0.038)$ & 0.010 & $(0.099)$ \\
\hline Years since Migration & 15.506 & $(5.653)$ & $14.833^{*}$ & $(5.459)$ & $16.728^{*}$ & $(5.911)$ \\
\hline Employment spell in Germany & 0.876 & $(0.330)$ & 0.840 & $(0.367)$ & 0.887 & $(0.317)$ \\
\hline Local unemployment rate & 9.228 & $(3.380)$ & 9.283 & $(3.942)$ & $8.522^{*}$ & $(3.781)$ \\
\hline Local native population density/1000 & 0.501 & $(0.708)$ & $1.158^{*}$ & $(0.911)$ & $1.464^{*}$ & $(1.053)$ \\
\hline Ln(local immigrant group size) & 8.999 & $(0.996)$ & $9.964^{*}$ & $(1.000)$ & $10.360^{*}$ & $(1.068)$ \\
\hline Nr. of Observations & \multicolumn{2}{|c|}{468} & \multicolumn{2}{|c|}{705} & \multicolumn{2}{|c|}{709} \\
\hline
\end{tabular}

Source: SOEP 1987, German census 1987, own calculations.

Note: Standard deviations in parentheses. Local level is county level. Ethnic concentration is the size of the ethnic group relative to the population in each county. A low (medium, high) co-ethnic concentration is defined as a county with a local co-ethnic fraction which is lower (at least as high, at least twice as high) as the national population share of the respective group. * Statistically different from low co-ethnic concentration mean at the 5 percent confidence level. 
Table 3: Ethnic Identity and Co-Ethnic Concentration

\begin{tabular}{|c|c|c|c|c|}
\hline & \multicolumn{2}{|c|}{ German Identity } & \multicolumn{2}{|c|}{ Minority Identity } \\
\hline & (1) & $(2)$ & (3) & $(4)$ \\
\hline Ln(local ethnic group size) & $\begin{array}{l}-0.042 \\
(0.086)\end{array}$ & & $\begin{array}{c}0.119 \\
(0.080)\end{array}$ & \\
\hline \multicolumn{5}{|l|}{ Low local ethnic concentration (ref.) } \\
\hline Medium local ethnic concentration & & $\begin{array}{c}-0.444^{* * *} \\
(0.137)\end{array}$ & & $\begin{array}{c}0.138 \\
(0.102)\end{array}$ \\
\hline High local ethnic concentration & & $\begin{array}{c}-0.478^{* * *} \\
(0.148)\end{array}$ & & $\begin{array}{c}0.335^{* * *} \\
(0.108)\end{array}$ \\
\hline Female & $\begin{array}{c}-0.064 \\
(0.043)\end{array}$ & $\begin{array}{c}-0.064 \\
(0.043)\end{array}$ & $\begin{array}{c}0.020 \\
(0.040)\end{array}$ & $\begin{array}{c}0.021 \\
(0.040)\end{array}$ \\
\hline \multicolumn{5}{|l|}{ No schooling in home country (ref.) } \\
\hline College in h.c. & $\begin{array}{l}0.383^{* *} \\
(0.186)\end{array}$ & $\begin{array}{l}0.389^{* *} \\
(0.184)\end{array}$ & $\begin{array}{c}-0.348 \\
(0.223)\end{array}$ & $\begin{array}{c}-0.342 \\
(0.220)\end{array}$ \\
\hline Vocational training in h.c. & $\begin{array}{c}0.151^{*} \\
(0.087)\end{array}$ & $\begin{array}{c}0.151^{*} \\
(0.087)\end{array}$ & $\begin{array}{l}-0.095 \\
(0.090)\end{array}$ & $\begin{array}{l}-0.099 \\
(0.090)\end{array}$ \\
\hline Complete schooling in h.c. & $\begin{array}{l}-0.031 \\
(0.082)\end{array}$ & $\begin{array}{c}-0.033 \\
(0.083)\end{array}$ & $\begin{array}{c}0.078 \\
(0.091)\end{array}$ & $\begin{array}{c}0.076 \\
(0.091)\end{array}$ \\
\hline Incomplete schooling in h.c. & $\begin{array}{c}0.106 \\
(0.072)\end{array}$ & $\begin{array}{c}0.108 \\
(0.072)\end{array}$ & $\begin{array}{c}-0.041 \\
(0.073)\end{array}$ & $\begin{array}{c}-0.042 \\
(0.074)\end{array}$ \\
\hline \multicolumn{5}{|l|}{ Some schooling in Germany (ref.) } \\
\hline No degree in G. & $\begin{array}{c}-0.157^{* *} \\
(0.077)\end{array}$ & $\begin{array}{c}-0.157^{* *} \\
(0.077)\end{array}$ & $\begin{array}{c}0.151^{*} \\
(0.087)\end{array}$ & $\begin{array}{c}0.149^{*} \\
(0.087)\end{array}$ \\
\hline Higher degree in G. & $\begin{array}{c}0.665^{* * *} \\
(0.158)\end{array}$ & $\begin{array}{c}0.613^{* * *} \\
(0.153)\end{array}$ & $\begin{array}{c}-0.572^{* * *} \\
(0.196)\end{array}$ & $\begin{array}{c}-0.571^{* * *} \\
(0.194)\end{array}$ \\
\hline Employment spell in G. & $\begin{array}{c}0.133 \\
(0.086)\end{array}$ & $\begin{array}{c}0.128 \\
(0.086)\end{array}$ & $\begin{array}{l}-0.113 \\
(0.076)\end{array}$ & $\begin{array}{c}-0.113 \\
(0.076)\end{array}$ \\
\hline Years since migration & $\begin{array}{c}0.013^{* * *} \\
(0.005)\end{array}$ & $\begin{array}{c}0.013^{* * *} \\
(0.005)\end{array}$ & $\begin{array}{c}-0.012^{* *} \\
(0.005)\end{array}$ & $\begin{array}{c}-0.012^{* *} \\
(0.005)\end{array}$ \\
\hline Age at migration & $\begin{array}{c}-0.041^{* * *} \\
(0.010)\end{array}$ & $\begin{array}{c}-0.042^{* * *} \\
(0.010)\end{array}$ & $\begin{array}{c}0.039 * * * \\
(0.009)\end{array}$ & $\begin{array}{c}0.039 * * * \\
(0.009)\end{array}$ \\
\hline Age at migration squared/1000 & $\begin{array}{l}0.399 * * \\
(0.167)\end{array}$ & $\begin{array}{l}0.413^{* *} \\
(0.167)\end{array}$ & $\begin{array}{c}-0.394^{* *} \\
(0.166)\end{array}$ & $\begin{array}{c}-0.395^{* *} \\
(0.166)\end{array}$ \\
\hline Turkish (ref.) & & & & \\
\hline Ex-Yugoslavian & $\begin{array}{l}0.272^{* *} \\
(0.111)\end{array}$ & $\begin{array}{c}0.289^{* * *} \\
(0.082)\end{array}$ & $\begin{array}{c}-0.076 \\
(0.115)\end{array}$ & $\begin{array}{c}-0.191^{* *} \\
(0.088)\end{array}$ \\
\hline Italian & $\begin{array}{c}0.124 \\
(0.114)\end{array}$ & $\begin{array}{c}0.147 \\
(0.089)\end{array}$ & $\begin{array}{c}0.038 \\
(0.117)\end{array}$ & $\begin{array}{l}-0.118 \\
(0.103)\end{array}$ \\
\hline Greek & $\begin{array}{c}-0.299 * * \\
(0.146)\end{array}$ & $\begin{array}{c}-0.286^{* * *} \\
(0.103)\end{array}$ & $\begin{array}{c}0.481^{* * *} \\
(0.144)\end{array}$ & $\begin{array}{l}0.250^{* *} \\
(0.106)\end{array}$ \\
\hline Constant & $\begin{array}{c}0.382 \\
(0.638)\end{array}$ & $\begin{array}{c}0.105 \\
(0.172)\end{array}$ & $\begin{array}{c}-0.558 \\
(0.579)\end{array}$ & $\begin{array}{l}0.329^{* *} \\
(0.165)\end{array}$ \\
\hline County FE & yes & yes & yes & yes \\
\hline$N$ & 1,882 & 1,882 & 1,882 & 1,882 \\
\hline adj. R-sq & 0.251 & 0.255 & 0.199 & 0.201 \\
\hline AIC & 4780.420 & 4770.872 & 4906.980 & 4903.595 \\
\hline BIC & 5112.826 & 5108.817 & 5239.385 & 5241.540 \\
\hline
\end{tabular}

Source: SOEP 1987, German census 1987, own calculations.

Notes: Standard errors, in parentheses, are adjusted to reflect within-county/ethnicity clustering. Local level is county level. The dependent variables are measured on a five-point scale from "no" (1) to "complete" (5) identification with the host (home) country and here included as a standardized quasi-metric measure. A low (medium, high) ethnic concentration is defined as a county with a local co-ethnic fraction which is lower (at least as high, at least twice as high) as the national population share of the respective ethnic group.

${ }^{*} p<.10 ;{ }^{* *} p<.05 ; * * * p<.01$ 
Table 4: Instrumental Variable Estimation - German Identity

\begin{tabular}{|c|c|c|c|c|}
\hline & \multicolumn{4}{|c|}{ German Identity } \\
\hline & (1) & (2) & (3) & $(4)$ \\
\hline & OLS & IV & IV-1stPROBIT & Red. Form \\
\hline Medium/high local ethnic concentration & $\begin{array}{c}-0.456^{* * *} \\
(0.132)\end{array}$ & $\begin{array}{c}-0.371 \\
(0.494)\end{array}$ & $\begin{array}{c}-0.509^{* *} \\
(0.223)\end{array}$ & \\
\hline 1970 medium/high local ethnic concentr. & & & & $\begin{array}{l}-0.066 \\
(0.090)\end{array}$ \\
\hline Controls & yes & yes & yes & yes \\
\hline Country of origin FE & yes & yes & yes & yes \\
\hline County FE & yes & yes & yes & yes \\
\hline \multicolumn{5}{|l|}{ First stage: } \\
\hline 1970 medium/high local ethnic concentr. & & $\begin{array}{c}0.179 * * * \\
(0.066)\end{array}$ & $\begin{array}{c}1.947^{* * *} \\
(0.266)\end{array}$ & \\
\hline Partial R-sq. & & 0.890 & & \\
\hline F-stat & & 6.743 & & \\
\hline $\mathrm{N}$ & 1,882 & 1,882 & 1,882 & 1,882 \\
\hline adj. R-sq & 0.255 & 0.255 & & 0.251 \\
\hline
\end{tabular}

Source: SOEP 1987, German census 1987, own calculations.

Notes: Standard errors, in parentheses, are adjusted to reflect within-county/ethnicity clustering. Local level is county level. Dependent variables are standardized. A low (medium, high) ethnic concentration is defined as a county with a local coethnic fraction which is lower (at least as high, at least twice as high) as the national population share of the respective group. In IV models, local ethnic concentration measure is instrumented using the respective co-ethnic concentration in 1970. Model 2 employs a linear model in the first stage, Model 3 uses a probit regression in the first stage Model 3 does not contain county fixed effects in the first stage estimation.

${ }^{*} p<.10 ;{ }^{* *} p<.05 ; * * * p<.01$

Table 5: Instrumental Variable Estimation - Minority Identity

\begin{tabular}{|c|c|c|c|c|}
\hline & \multicolumn{4}{|c|}{ Minority Identity } \\
\hline & (1) & $(2)$ & (3) & $(4)$ \\
\hline & OLS & IV & IV-1stPROBIT & Red. Form \\
\hline High local ethnic concentration & $\begin{array}{l}0.215^{* *} \\
(0.092)\end{array}$ & $\begin{array}{c}0.220^{*} \\
(0.124)\end{array}$ & $\begin{array}{c}0.187 \\
(0.123)\end{array}$ & \\
\hline 1970 high local ethnic concentration & & & & $\begin{array}{c}0.076 \\
(0.048)\end{array}$ \\
\hline Controls & yes & yes & yes & yes \\
\hline Country of origin FE & yes & yes & yes & yes \\
\hline County FE & yes & yes & yes & yes \\
\hline \multicolumn{5}{|l|}{ First stage: } \\
\hline 1970 high local ethnic concentration & & $\begin{array}{c}0.348^{* * *} \\
(0.041)\end{array}$ & $\begin{array}{c}1.195^{* * *} \\
(0.143)\end{array}$ & \\
\hline $\begin{array}{l}\text { Partial R-sq. } \\
\text { F-stat }\end{array}$ & & $\begin{array}{c}0.880 \\
68.408\end{array}$ & & \\
\hline $\mathrm{N}$ & 1,882 & 1,882 & 1,882 & 1,882 \\
\hline adj. R-sq & 0.201 & 0.201 & & 0.199 \\
\hline
\end{tabular}

Source: SOEP 1987, German census 1987, own calculations.

Notes: Standard errors, in parentheses, are adjusted to reflect within-county/ethnicity clustering. Local level is county level. Dependent variables are standardized. A low (medium, high) ethnic concentration is defined as a county with a local coethnic fraction which is lower (at least as high, at least twice as high) as the national population share of the respective group. In IV models, local ethnic concentration measure is instrumented using the respective co-ethnic concentration in 1970. Model 2 employs a linear model in the first stage, Model 3 uses a probit regression in the first stage. Model 3 does not contain county fixed effects in the first stage estimation.

${ }^{*} p<.10 ; * * p<.05 ; * * * p<.01$ 